\title{
Age-related and sex-related changes in perfusion index in response to noxious electrical stimulation in healthy subjects
}

This article was published in the following Dove Press journal: Journal of Pain Research

10 February 2014

Number of times this article has been viewed

\author{
Toshiki Nishimura' \\ Aya Nakae ${ }^{2}$ \\ Masahiko Shibata ${ }^{3}$ \\ Takashi Mashimo ${ }^{4}$ \\ Yuji Fujino²
}

'Osaka University Medical School, 2Department of Anesthesiology and Intensive Care Medicine, ${ }^{3}$ Department of Pain Medicine, Osaka University Graduate School of Medicine, Suita, Japan; ${ }^{4}$ Toyonaka Municipal Hospital, Toyonaka, Japan
Correspondence: Aya Nakae

Department of Anesthesiology and Intensive Care Medicine, Osaka

University Graduate School of Medicine,

2-2, Yamadaoka, Suita, 565087I, Japan

$\mathrm{Tel}+81668792649$

Fax +81668792648

Email anakae@anes.med.osaka-u.ac.jp
Background: Even though pain is a subjective phenomenon, its objective evaluation in humans is important because subjects requiring pain evaluation may be unable to describe their pain intensity because of decreased awareness or impaired cognitive function. Previous reports indicate that the perfusion index (PI), which is calculated from pulse oximeter waveforms, has some utility in assessing pain. However, age-associated and sex-associated differences in change of PI have hitherto not been evaluated for assessment of pain. Therefore, we aimed to estimate the utility of age-related differences in PI change among healthy volunteers subjected to electrical stimulation.

Methods: We measured PI and pulse rate in 70 healthy volunteers exposed to gradually increasing electrical stimulation. The subjects were classified into four groups, ie, young men, young women, aged men, and aged women. Stimulation was stopped when subjects reached their pain tolerance threshold. The average PI and pulse rate were calculated 10 seconds before and after electrical stimulation and compared across the four groups. Changes in PI and pulse rate were analyzed using the paired $t$-test.

Results: The PI was significantly decreased in response to pain stimulation in young men $(P<0.0001)$, young women $(P=0.0002)$, and aged men $(P=0.0158)$. However, aged women failed to show significant changes in PI before or after stimulation. The pulse rate was not significantly altered in any of the groups.

Conclusion: PI may be an independent parameter reflecting the perception of noxious stimuli and could be used for objective evaluation of pain perception in healthy volunteers, except when it is used for pain evaluation in elderly women.

Keywords: noxious stimuli, perfusion index, objective evaluation, age difference, sex difference

\section{Introduction}

Various factors, such as pharmacological factors, ${ }^{1}$ psychological factors, ${ }^{2}$ personality traits, ${ }^{3}$ and presence of disease, ${ }^{4}$ cause pain in humans. Psychophysical methods for quantifying pain have been used to monitor a subject's pain perception. These methods have proven to be extremely valuable. Most subjects learn to rate their pain easily using visual analog/numerical rating scales that require certain basic cognitive and motor skills. However, these skills can be so diminished in certain individuals because of cognitive or motor dysfunction related to age, disease, or perioperative state, that pain remains unnoticed and untreated.

Many researchers have assessed the autonomic response to pain, which is most frequently accomplished by monitoring skin conductance or heart rate, to identify 
accurate nonverbal measures of pain. ${ }^{5,6}$ In fact, a number of studies have shown that applying stimuli induces the sympathetic nervous system, which results in increased heart rate, ${ }^{7}$ skin conductance, ${ }^{8}$ and vasomotor tone. ${ }^{9,10}$

Pulse oximetry is a noninvasive technique used to assess oxygen saturation, vasoconstriction, and pulse rate. The perfusion index (PI) is used to quantify pulse strength at the monitoring site and therefore provides an indirect and noninvasive measure of peripheral perfusion. PI is calculated by expressing the pulsatile signal (during arterial inflow) as a percentage of the nonpulsatile signal. Both signals are determined by the extent of infrared (940 nm) light absorbed by a pulse oximeter. ${ }^{11}$ The pulse oximetric waveform can be used to monitor the sympathetic response to noxious stimuli. ${ }^{10,11}$ However, various factors, such as age, sex, and peripheral perfusion, are known to affect the quality of data obtained by pulse oximetry. ${ }^{11}$ Nevertheless, pulse oximetry offers a noninvasive option for objectively evaluating pain perception.

It is well known that autonomic responses to noxious stimuli differ depending on age and sex. ${ }^{6,7}$ To our knowledge, this is the first study to measure the differences in autonomic responses to noxious stimuli induced by peripheral vasoconstriction using PI in young and aged, men and women.

The aim of the present study was to examine PI changes in healthy volunteers exposed to gradually increasing electrical $A \beta$ fiber stimulation, to determine the effect of age and sex on these responses, and to evaluate the advantages and limitations of PI as a complementary pain evaluation tool for the development of better pain evaluation guidelines.

\section{Materials and methods}

\section{Participants}

This study was approved by the research ethics committee at Osaka University Hospital. All participants provided their written informed consent. The subjects comprised 70 healthy volunteers (mean age 52.9 \pm 22.3 years, 35 women) who were recruited via advertisements. Subjects with a history of a neurological, psychiatric, or chronic pain disorder were excluded from the study. Subjects taking psychotropic or analgesic drugs during the course of the study were also excluded. The study was performed in a quiet room at $22^{\circ} \mathrm{C}-26^{\circ} \mathrm{C}$. The study session lasted approximately 10 minutes.

\section{Instruments and study design}

Electrical stimulation and perfusion index

Participants rested in the sitting position during the study. We used the Pain Vision System (PS-2100; Nipro Corporation,
Osaka, Japan), ${ }^{12}$ developed to estimate the patients' pain intensity as numbers on gradual $\mathrm{A} \beta$ fiber stimulation, where the patients are asked to report their pain threshold. Electrical stimulation was increased from $0 \mu \mathrm{A}$ to $256 \mu \mathrm{A}$ over 1 minute and was delivered to the forearm. First, the minimum detection threshold was measured for each participant (Figure 1A). A high value would have indicated that the subject had nerve damage. Second, the pain detection threshold was measured, and a reusable pulse oximeter sensor (Radical-7; Masimo, Tokyo, Japan) was placed on the left middle finger to measure the pulse rate and PI. These data were sent to a laptop computer using a serial cable, where they were digitally recorded and averaged every second using Masimo SET Sat Partner software (Masimo). Approximately 5 minutes after placing the sensors and explaining the electrical stimulation procedure to the participants, gradually increasing electrical stimulation was applied to the inside of the left forearm using the Pain Vision System. ${ }^{12}$ Participants were instructed to push a button when they experienced intolerable pain, at which point the stimulation was stopped. The procedure was repeated twice with an interval of sufficient duration to confirm that the PI had
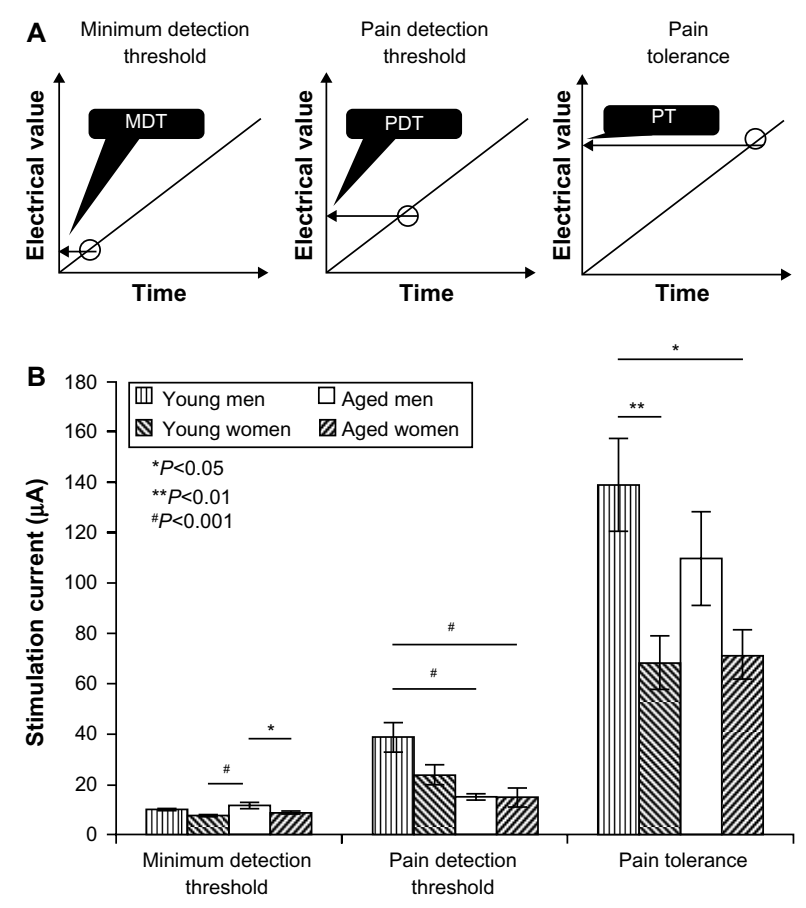

Figure I (A) Schematic for evaluation of pain threshold and tolerance. (B) Differences in electrical stimulation threshold in terms of minimum detection threshold, pain detection threshold, and pain tolerance.

Notes: (A) MDT was the value at which participants pushed the button when they experienced any kind of sensation (not pain). PDT was the value at which participants pushed the button immediately after they felt the sensation as pain. PT was the value at which participants pushed the button when they could not endure the pain. (B) Error bars represent the standard error of the mean. $* P<0.05$; $* * P<0.0$ I; ${ }^{*} P<0.00$ I.

Abbreviations: MDT, minimum detection threshold; PDT, pain detection threshold; PT, pain tolerance. 
returned to the baseline value before initiating the next stimulation. We recorded the stimulation intensity $(\mu \mathrm{A})$ for minimum detection threshold, pain detection threshold, pain tolerance, and mean PI 10 seconds before and after stimulation.

\section{Measurement variables}

Pre-stimulus (baseline) measurements were defined as the average values during a 10 -second time interval immediately before stimulation. Post-stimulus values were defined as the average values during a 10 -second time period immediately after stimulation. For evaluating percent change, parameters were normalized by calculating their percent change from the pre-stimulus average $(\%$ change $=100 \times$ [post-stimulus average]/[pre-stimulus average]). The mean values of the two trials were used for all analyses.

\section{Statistical analysis}

Changes in PI and pulse rate before and after stimulation were analyzed using the paired $t$-test. One-way analysis of variance with the Tukey-Kramer multiple comparison test was used to analyze the detection threshold, tolerance, and pre-stimulation and post-stimulation PI and pulse rate. Correlations were tested using the Pearson's correlation coefficient. A $P$-value $<0.05$ was considered to be statistically significant. The statistical analysis was performed using JMP version 9.01 software (SAS Institute Inc, Cary, $\mathrm{NC}$, USA). All data are shown as the mean \pm standard error of the mean.

\section{Results \\ Study population}

Data were analyzed from 64 of the original 70 subjects. Six subjects were excluded because of technical failure. We categorized the participants into two groups, ie, an aged group ( $\geq 60$ years) and a young group ( $<60$ years). Because 60 years is the retirement age in Japan, we chose this as the threshold for classification. In addition, we examined differences between men and women. Thus, we obtained four study groups, ie, aged men, aged women, young men, and young women. Demographic data for the 64 subjects are shown in Table 1.

Table I Age distribution of study participants

\begin{tabular}{lllll}
\hline & \multicolumn{3}{l}{ Women } & Men \\
\cline { 2 - 5 } & $\mathrm{N}$ & Age* & $\mathrm{N}$ & Age* \\
\hline Aged & 16 & $(73.7 \pm 5.65)$ & 16 & $(73.8 \pm 7.20)$ \\
Young & 16 & $(35.1 \pm 9.82)$ & 16 & $(29.1 \pm 6.63)$ \\
Total & 32 & $(54.4 \pm 21.1)$ & 32 & $(51.4 \pm 23.7)$ \\
\hline
\end{tabular}

Note: $*$ The age is shown as years; mean \pm SD.

Abbreviation: SD, standard deviation.

\section{Electrical stimulation}

The mean values for minimum detection threshold, pain detection threshold, and pain tolerance are shown in Figure 1B. We observed a significant difference in the minimum detection threshold among the groups $(F[1,3,63]=6.19, P=0.001)$; post hoc comparison revealed that the minimum detection threshold was higher in aged men than in aged women $(P=0.0224)$ and young women $(P=0.0007)$. The pain detection threshold was also significantly different between the groups $(F[1,3,63], P=0.0003)$, being higher in the young men than in the aged men $(P=0.0008)$ and aged women $(P=0.0007)$. We also observed a significant difference in pain tolerance between the groups $(F[1,3,63]=5.14, P=0.0031)$. Pain tolerance was higher in young men compared with young women $(P=0.0074)$ and aged women ( $P=0.0111$; Figure 1B).

\section{Change in perfusion index and pulse rate}

The mean PI and pulse rate values are shown in Figures 2 and 3, respectively. We observed a significantly decreased PI in response to electrical stimulation in young men $(P<0.0001)$, young women $(P=0.0002)$, and aged men $(P=0.0158)$. However, these values were not significantly different in aged women before and after stimulation (Figure 2). The baseline PI was significantly different between the groups $(F[1,3,63]=3.62, P=0.0180)$, and was higher in aged men than in young women $(P=0.0119)$. The PI in the post-stimulation period was significantly different between the groups $(F[1,3,63]=8.83, P<0.0001)$, being significantly lower in young men than in aged men $(P=0.0039)$ and aged women $(P=0.0095)$. Moreover, the PI values were significantly lower in young women than in aged men $(P=0.0011)$ and aged women $(P=0.0028$; Figure 3$)$. The percent change in PI was significantly different between the groups $(F[1,3,63]=15.3, P<0.0001)$; it was significantly lower in young men than in aged men $(P<0.0001)$ and aged women $(P<0.0001)$ and significantly lower in young women than in aged women $(P=0.0009)$. However, we observed no significant differences in pulse rate before or after stimulation for any of the groups (Figure 4). There was no significant difference in baseline pulse rate; nevertheless, a significant difference was found in pulse rate between young men and aged men after stimulation (Figure 3). Further, there was no significant difference in percent change for pulse rate in any of the groups. In other words, the stimulation was too small to increase the participants' pulse rate (Figure 3B). 

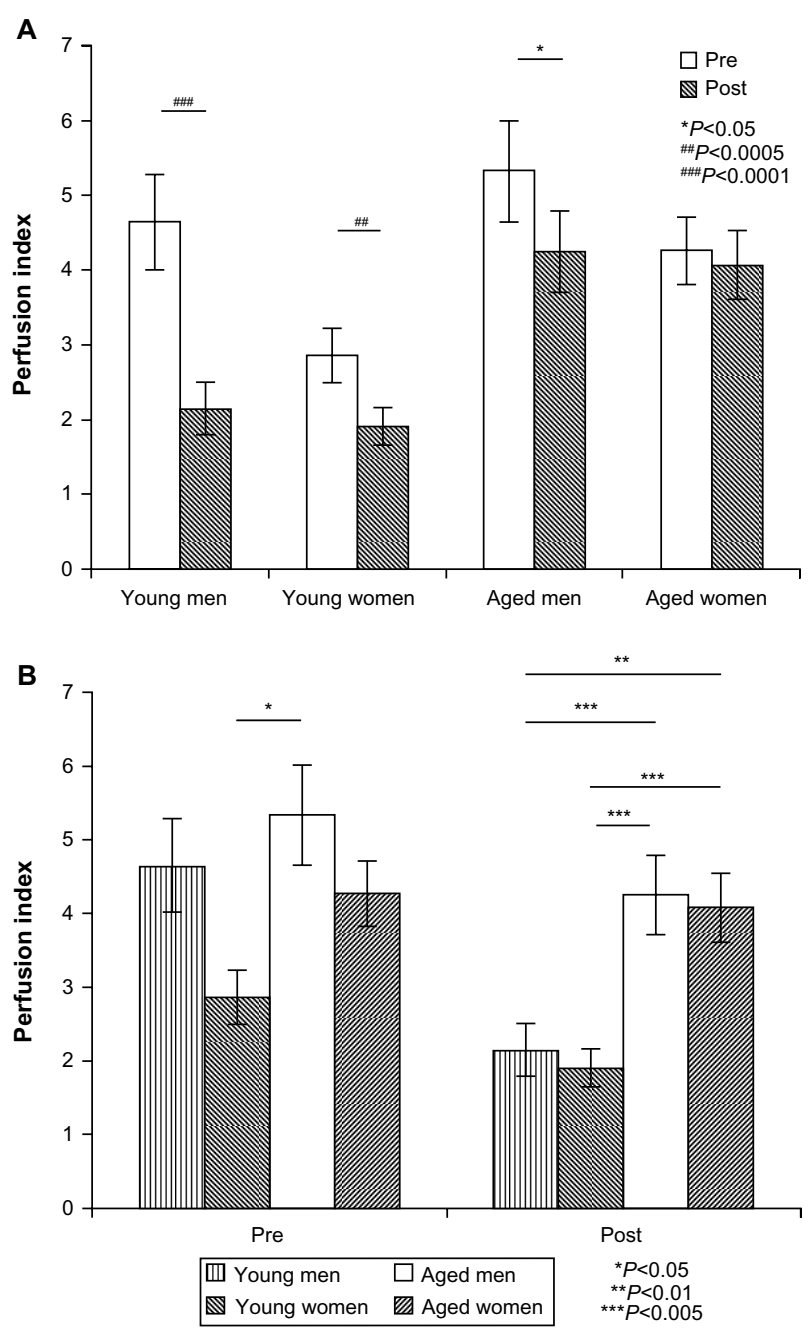

Figure 2 (A) Differences in perfusion index before and after electrical stimulation in each group. (B) Perfusion index change before and after electrical stimulation in each group.

Notes: Error bars represent the standard error of the mean. $* P<0.05$; $* * P<0.0$ I; $* * * P<0.005 ; \# P<0.0005 ; \ldots+\ldots<0.0001$.

\section{Effect of age on autonomic response to electrical stimulation}

Next, we examined the correlation between age, PI, and percent PI change using Pearson's correlation. A significant correlation was observed between baseline PI and age in women $(P=0.0036)$, but not for all subjects $(P=0.184)$ or men $(P=0.737$; Table 2). Moreover, a significant correlation between PI in the post-stimulation period and age was observed for all subjects $(P<0.0001)$, men $(P=0.0036)$, and women $(P<0.0001)$. A significant correlation was also obtained between percent PI change and age in all the subjects $(P<0.0001)$, in men alone $(P<0.0001)$, and in women alone $(P<0.0001)$. We also analyzed the sexrelated differences in PI values and percent PI change for all subjects (Table 3). Significant differences were observed
A

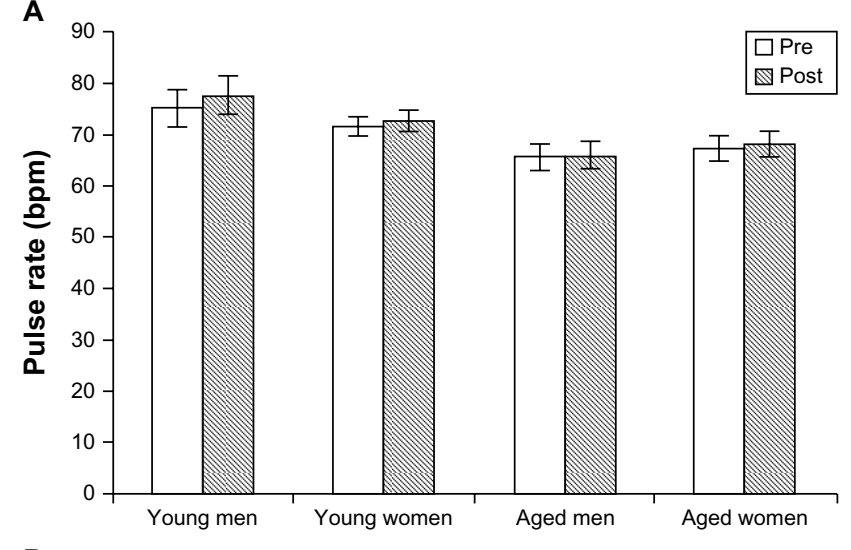

B

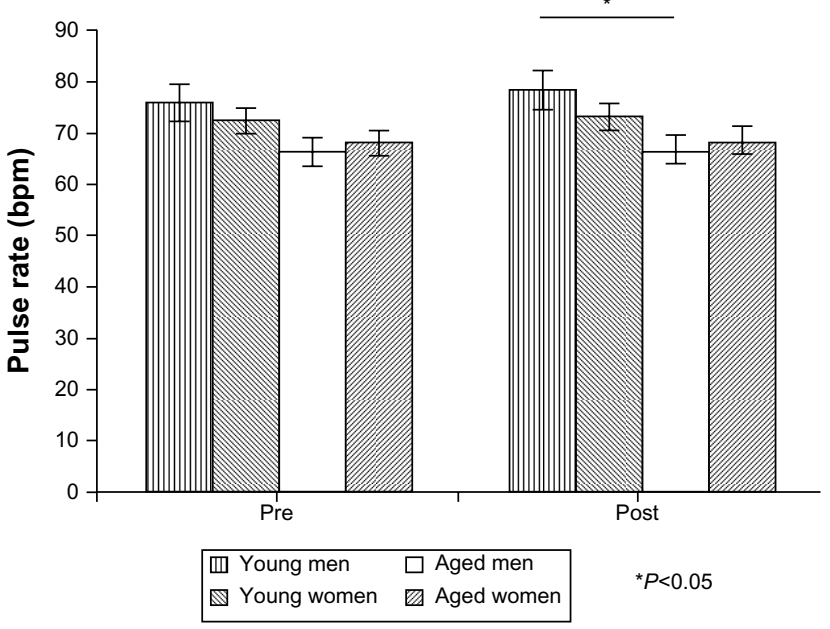

Figure 3 (A) Differences in pulse rate before and after electrical stimulation in each group. (B) Pulse rate changes before and after electrical stimulation in each group. Notes: Error bars represent the standard error of the mean. ${ }^{*} P<0.05$.

Abbreviation: bpm, beats per minute.

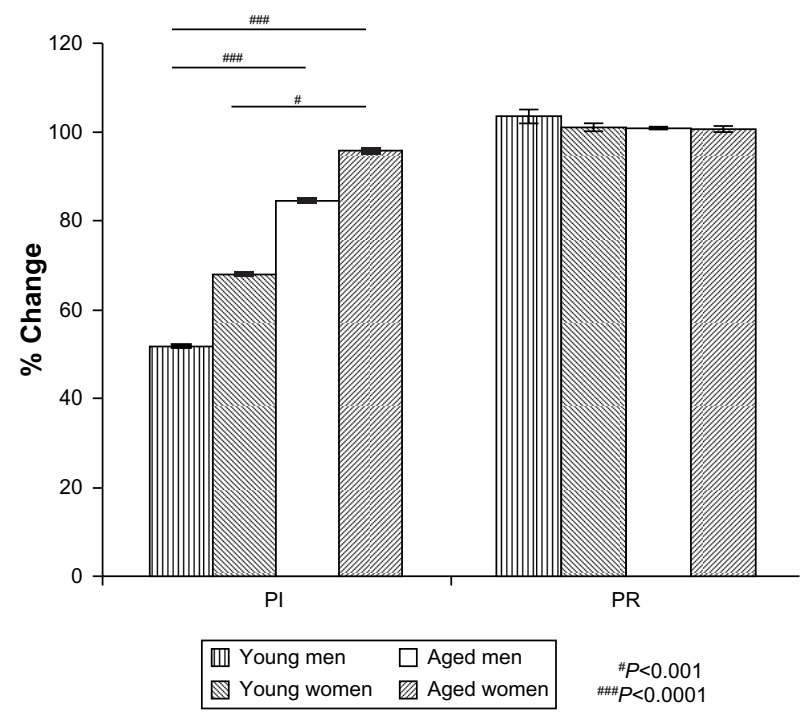

Figure 4 Percentage of PI change and PR change in each group. Notes: Percent change $=100 \times$ (post-stimulation value)/(pre-stimulation value). Error bars represent the standard error of the mean. ${ }^{\#} P<0.00 \mathrm{I} ;{ }^{\#} P<0.000 \mathrm{I}$. Abbreviations: PI, perfusion index; PR, pulse rate. 
Table 2 Correlation between perfusion index and age of participants by sex

\begin{tabular}{llll}
\hline & $\begin{array}{l}\text { Before } \\
\text { intervention }\end{array}$ & $\begin{array}{l}\text { After } \\
\text { intervention }\end{array}$ & $\begin{array}{l}\text { Percent } \\
\text { change }\end{array}$ \\
\hline Women & $0.431^{*}$ & $0.630^{* * *}$ & $-0.665^{* * * *}$ \\
Men & 0.0618 & $0.499^{* *}$ & $-0.663^{* * *}$ \\
Total & 0.168 & $0.630^{* * *}$ & $-0.665^{* * *}$ \\
\hline
\end{tabular}

Notes: $* P<0.05 ; * * P<0.005 ; * * * P<0.0001$

between men and women in terms of baseline PI and percent changes in PI.

There was a significant correlation between baseline pulse rate and age in female subjects $(P=0.0356)$ and all subjects ( $P=0.0146)$, but not in male subjects $(P=0.143$; Table 4$)$. Further, a significant correlation was observed between pulse rate after stimulation and age in all subjects $(P=0.0099)$ and in female subjects $(P=0.0493)$ but not in male subjects $(P=0.0937)$. No significant correlation was found for any of the groups in terms of pulse rate changes.

\section{Discussion}

We observed that PI decreased with noxious electrical stimulation even though the magnitude of stimulation was too small to induce changes in pulse rate. Moreover, the magnitude of response to electrical stimulation was different between the groups. PI did not change with stimulation in aged women. Even though PI is a good objective indicator, its usefulness as a complementary pain evaluation tool should be monitored carefully when evaluating aged women.

Individual differences do exist in terms of sensitivity to pain. Various population-based studies suggest that women are more likely to experience chronic pain syndrome and tend to report more severe pain than men. ${ }^{13-15}$ In our study, pain tolerance was significantly higher in young men than in young women. However, in the elderly, there was no difference between males and females. Previous reviews related to sex differences concluded that women had significantly greater pain sensitivity than men, but they also acknowledged that these differences were not always consistent. Age-related differences may also be an important contributing factor. In our

Table 3 Different values of perfusion index by sex

\begin{tabular}{llll}
\hline & $\begin{array}{l}\text { Before } \\
\text { intervention } \\
\text { (mean } \pm \text { SEM) }\end{array}$ & $\begin{array}{l}\text { After } \\
\text { intervention } \\
\text { (mean } \pm \text { SEM) }\end{array}$ & $\begin{array}{l}\text { Percent } \\
\text { change } \\
\text { (mean } \pm \text { SEM) }\end{array}$ \\
\hline Women & $3.56 \pm 0.312$ & $2.98 \pm 0.325$ & $18.1 \pm 3.97$ \\
Men & $4.99 \pm 0.459$ & $3.20 \pm 0.372$ & $31.7 \pm 4.79$ \\
$P$-value & $P<0.05$ & $n s$ & $P<0.05$ \\
\hline
\end{tabular}

Abbreviations: SEM, standard error of the mean; ns, not significant.
Table 4 Correlation between age and pulse rate of participants by sex

\begin{tabular}{llll}
\hline & $\begin{array}{l}\text { Before } \\
\text { intervention }\end{array}$ & $\begin{array}{l}\text { After } \\
\text { intervention }\end{array}$ & $\begin{array}{l}\text { Percent } \\
\text { change }\end{array}$ \\
\hline Women & $-0.373^{*}$ & $-0.530^{*}$ & -0.0530 \\
Men & -0.265 & -0.301 & -0.195 \\
Total & $-0.373^{*}$ & $-0.350^{*}$ & -0.0530 \\
\hline
\end{tabular}

Note: $* P<0.05$

study, the pain detection threshold was significantly higher in young men than in aged men, even though pain tolerance was not significantly different between these groups. Higher tolerance implies a longer duration of stimulation. Thus, some of the effects observed in male subjects could have probably resulted from the extended duration of stimulation.

Several studies have shown that noxious stimuli affect autonomic responses. Some studies have measured the autonomic response via pulse oximetry. ${ }^{11}$ Heart rate variability may be useful in measurement of sympathetic tone during general anesthesia, ${ }^{16}$ especially during painful events. The Surgical Stress index, which indicates the level of surgical stress in anesthetized patients, is calculated using the plethysmographic pulse wave amplitude and normalized heartbeat interval. Huiku et al emphasize that the plethysmographic pulse wave amplitude is twice the heartbeat interval. ${ }^{17,18}$ Even in general anesthesia, PI may be a better indicator of noxious stimuli than changes in heartbeat.

Thus, our results confirm the findings of a number of previous studies ${ }^{9-11}$ identifying various autonomic parameters that can be used to measure pain sensation. The stimulation strategy used in this study is different from that used in previous studies; we used a more clinically relevant strategy in the form of electrical stimulation of $A \beta$ fibers, which is relatively less painful and noninvasive. Indeed, changes in pulse rate were not observed before or after stimulation (Figure 3) in our study, as compared with previous studies. . $^{9,10,19,20}$ The cold and thermal pain sensations routinely used in pain stimulation experiments are sufficiently severe that heart rate or pulse rate changes are usually observed. The results of our study confirm that changes in PI are independent of pulse rate.

Skin conductance, which measures the electrical conductance of the skin and varies with skin moisture content, has been reported as another independent promising indicator of postoperative pain in children ${ }^{19}$ and subjects who cannot express their pain. A postoperative study comparing the differences between skin conductance and surgical stress index in pain assessment showed that these parameters could only assess moderate to severe pain with moderate sensitivity and 
specificity and that their prediction accuracies were similar. ${ }^{5}$ Another study suggested that assessing multiple parameters is more advantageous than assessing a single parameter. ${ }^{20}$ In that study, peripheral vasoconstriction assessed using pulse oximetry and skin conductance could effectively detect the autonomic response to noxious stimuli. Thus, a combination of skin conductance and PI might be a valuable approach for effective prediction of pain perception.

The study population is another important parameter. A previous Japanese study demonstrated that the prevalence of chronic musculoskeletal pain was highest in subjects aged $30-50$ years, ${ }^{21}$ and the prevalence of chronic pain is generally high in the elderly. ${ }^{22}$ Moreover, age-related and sex-related differences are associated with the autonomic response and microcirculation ${ }^{23}$ because of differences in regulation of peripheral vascular resistance. Previous reports showed that acute pain affected sympathovagal balance, which differs according to age and sex. ${ }^{5}$ Further, age and sex have been reported to affect the autonomic and hemodynamic responses to pain. ${ }^{6,7}$ To our knowledge, this study is the first to report that autonomic responses to weak noxious stimuli do not alter heart rate in the elderly. Therefore, age-related and sex-related differences should be considered when evaluating pain perception using autonomic parameters. Previous reports showed that reflex peripheral vasoconstriction was diminished in older men. ${ }^{24}$ The difference in PI change between young and elderly men observed in our study could be attributed to reflex peripheral vasoconstriction. Another study showed that augmented control of vasoconstriction in postmenopausal women was reversed by estrogen therapy. ${ }^{25}$ Differences between young and elderly women might therefore be caused by changes in estrogen levels. Previous studies have reported that heart rate changes in response to experimental pain only in male volunteers ${ }^{7}$ and in patients with lower back pain. ${ }^{6}$ In our study, we found that autonomic responses as measured by PI decreased significantly in young women and elderly men, but not in elderly women.

Even though pain is a complex multidimensional event that includes sensory and emotional components, using $\mathrm{A} \beta$ fiber electrical stimulation might be a better design strategy than heat or cold stimulation because the stimulation is less intense and does not increase pulse rate. However, it would be crucial to evaluate the advantages and disadvantages of both PI and pulse rate.

In conclusion, we have shown that noxious electrical $\mathrm{A} \beta$ pattern stimulation decreases PI but not pulse rate. The percent reduction in PI was highest in young male volunteers and lowest in aged female volunteers. These results indicate that PI may independently reflect the perception of noxious stimuli and may be a candidate parameter for objective evaluation of pain perception. However, our results also indicate that age-related and sex-related differences affect change in PI. Further studies evaluating the differences associated with age and sex are required in order to standardize the autonomic response to noxious stimuli before using PI as an objective marker of pain.

\section{Acknowledgments}

The authors thank Miss Sakurai and Miss Kimura for their excellent assistance with this work. This study was conducted in the Department of Anesthesiology and Intensive Care Medicine, Osaka University Graduate School of Medicine, Suita, Osaka, Japan, and was supported by Grant-in-Aid for Exploratory Research (236597430) from the Ministry of Education, Culture, Sports, Science and Technology, Japan, and by the Global COE Program, "Center of Human-Friendly Robotics Based on Cognitive Neuroscience" of the Ministry of Education, Culture, Sports, Science, and Technology, Japan.

\section{Disclosure}

This study was presented at the 34th Japanese Association for the Study of Pain (JASP) (a chapter of the International Association for the Study of Pain) meeting, Kumamoto, Japan, in July 2012. Otherwise, the authors report no conflicts of interest in this work.

\section{References}

1. Kawai S, Uchida E, Kondo M, et al. Efficacy and safety of ketoprofen patch in patients with rheumatoid arthritis: a randomized double-blind placebo-controlled study. J Clin Pharmacol. 2010;50(10):1171-1179.

2. Loggia ML, Mogil JS, Bushnell MC. Empathy hurts: compassion for another increases both sensory and affective components of pain perception. Pain. 2008;136(1-2):168-176.

3. Schweinhardt P, Seminowicz DA, Jaeger E, Duncan GH, Bushnell MC. The anatomy of the mesolimbic reward system: a link between personality and the placebo analgesic response. J Neurosci. 2009;29(15): $4882-4887$.

4. Lowenstein L, Vardi Y, Deutsch M, et al. Vulvar vestibulitis severity assessment by sensory and pain testing modalities. Pain. 2004;107(1-2): $47-53$.

5. Ledowski T, Ang B, Schmerbeck T, Rhodes J. Monitoring of sympathetic tone to assess postoperative pain: skin conductance versus surgical stress index. Anaesthesia. 2009;64(7):727-731.

6. Tousignant-Laflamme Y, Marchand S. Sex differences in cardiac and autonomic response to clinical and experimental pain in LBP patients. Eur J Pain. 2006;10(7):603-614.

7. Tousignant-Laflamme Y, Rainville P, Marchand S. Establishing a link between heart rate and pain in healthy subjects: a gender effect. $J$ Pain. 2005;6(6):341-347.

8. Dube AA, Duquette M, Roy M, Lepore F, Duncan G, Rainville P. Brain activity associated with the electrodermal reactivity to acute heat pain. Neuroimage. 2009;45(1):169-180. 
9. Awad AA, Ghobashy MA, Stout RG, Silverman DG, Shelley KH. How does the plethysmogram derived from the pulse oximeter relate to arterial blood pressure in coronary artery bypass graft patients? Anesth Analg. 2001;93(6):1466-1471.

10. Hamunen K, Kontinen V, Hakala E, Talke P, Paloheimo M, Kalso E. Effect of pain on autonomic nervous system indices derived from photoplethysmography in healthy volunteers. Br J Anaesth. 2012;108(5): 838-844.

11. Korhonen I, Yli-Hankala A. Photoplethysmography and nociception. Acta Anaesthesiol Scand. 2009;53(8):975-985.

12. Matsumura H, Imai R, Gondo M, Watanabe K. Evaluation of pain intensity measurement during the removal of wound dressing material using 'the PainVision ${ }^{\mathrm{TM}}$ system' for quantitative analysis of perception and pain sensation in healthy subjects. Int Wound J. 2012;9(4):451-455.

13. Blyth FM, March LM, Brnabic AJ, Jorm LR, Williamson M, Cousins MJ. Chronic pain in Australia: a prevalence study. Pain. 2001;89(2-3):127-134.

14. Breivik H, Collett B, Ventafridda V, Cohen R, Gallacher D. Survey of chronic pain in Europe: prevalence, impact on daily life, and treatment. Eur J Pain. 2006;10(4):287-333.

15. Eriksen J, Jensen MK, Sjogren P, Ekholm O, Rasmussen NK. Epidemiology of chronic non-malignant pain in Denmark. Pain. 2003;106(3):221-228.

16. Latson TW, O'Flaherty D. Effects of surgical stimulation on autonomic reflex function: assessment of changes in heart rate variability. $\mathrm{Br} J$ Anaesth. 1993;70(3):301-305.

17. Huiku H, Uutela K, van Gils M, et al. Assessment of surgical stress during general anaesthesia. Br J Anaesth. 2007;98(4):447-455.
18. Paloheimo MPJ, Sahanne S, Uutela KH. Autonomic nervous system state: the effect of general anaesthesia and bilateral tonsillectomy after unilateral infiltration of lidocaine. Br J Anaesth. 2010;104(5): $587-595$.

19. Hullett B, Chambers N, Preuss J, et al. Monitoring electrical skin conductance. A tool for the assessment of postoperative pain in children? Anesthesiology. 2009;111(3):513-517.

20. Treister R, Kliger M, Zuckerman G, Aryeh IG, Eisenberg E. Differentiating between heat pain intensities: the combined effect of multiple autonomic parameters. Pain. 2012;153(9):1807-1814.

21. Nakamura M, Nishiwaki Y, Ushida T, Toyama Y. Prevalence and characteristics of chronic musculoskeletal pain in Japan. J Orthop Sci. 2011;16(4):424-432.

22. Rastogi R, Meek BD. Management of chronic pain in elderly, frail patients: finding a suitable, personalized method of control. Clin Interv Aging. 2013;8:37-46.

23. Hart EC, Joyner MJ, Wallin BG, et al. Age-related differences in the sympathetic-hemodynamic balance in men. Hypertension. 2009;54(1): $127-133$.

24. Kenney WL, Armstrong CG. Reflex peripheral vasoconstriction is diminished in older men. J Appl Physiol (1985). 1996;80(2):512-515.

25. Fadel PJ, Wang Z, Watanabe H, Arbique D, Vongpatanasin W, Thomas GD. Augmented sympathetic vasoconstriction in exercising forearms of postmenopausal women is reversed by estrogen therapy. J Physiol. 2004;561 Pt 3:893-901.
Journal of Pain Research

\section{Publish your work in this journal}

The Journal of Pain Research is an international, peer-reviewed, open access, online journal that welcomes laboratory and clinical findings in the fields of pain research and the prevention and management of pain. Original research, reviews, symposium reports, hypothesis formation and commentaries are all considered for publication.

\section{Dovepress}

The manuscript management system is completely online and includes a very quick and fair peer-review system, which is all easy to use. Visit http://www.dovepress.com/testimonials.php to read real quotes from published authors. 